\title{
O PROJETO POLÍTICO-PEDAGÓGICO EM SUA CONSTRUÇÃO E IMPLANTAÇÃO COMPARTILHADA: O ESTUDO DE CASO DE UMA COMUNIDADE ESCOLAR
}

\author{
Samuel Robaert \\ Universidade Federal de Santa Maria, Brasil. \\ Marilene Gabriel Dalla Corte \\ Universidade Federal de Santa Maria, Brasil.
}

\begin{abstract}
Resumo
Este trabalho apresenta uma abordagem reflexiva sobre as concepções dos gestores, professores e demais integrantes de uma escola de educação básica do município de Três Passos, RS, acerca do projeto político-pedagógico, no sentido de verificar como interfere nas decisões tomadas na escola e na concretização de ações que visem à implantação das ideias e pressupostos contidos neste documento. Desde a Lei de Diretrizes e Bases da Educação (LDB/96) cabe as instituições escolares se apropriarem dos princípios de autonomia, coletividade e participação para a construção e consecução do projeto político-pedagógico, entretanto, passados vários anos, permanecem muitos equívocos e dúvidas quanto à elaboração e a implantação do mesmo. Com esta pesquisa constatou-se que o projeto político-pedagógico não se constitui, necessariamente, um documento norteador dos pressupostos e ações educacionais na escola, faltando, efetivamente, o espaço de compartilhamento, de reflexão e de [re]definição das ações educacionais.

Palavras-chave: gestão escolar, projeto político-pedagógico, comunidade escolar.

\section{THE POLITICAL PEDAGOGIC PROJECT IN YOUR BUILDING SHARED AND IMPLEMENTATION: THE CASE STUDY OF A COMMUNITY SCHOOL}

\begin{abstract}
This work presents reflexive approach about the manager's conceptions, teachers and others members from a middle school of Três Passos city, RS, about politic pedagogical project in order to verify how interfere in decisions made at school and in the realization of actions for the implementation of the ideas and assumptions contained herein. Since the Law of Directives and Bases of Education (LDB/96) school responsibility appropriating the principles of autonomy, collectivity and participation for the construction and achievement of the politic pedagogical project, however, after several years, many misconceptions and doubts remain as to the preparation and implementation of the politic pedagogical project. With this research we realized that the politic pedagogical project does not necessarily constitute a guiding document of the assumptions and educational activities at school, missing, effectively, space sharing, reflection and re-definition of educational activities.
\end{abstract}

Key-words: school management, political pedagogic project, school community. 


\section{Introdução}

s compromissos da escola com as políticas públicas para a educação pressupõem um amplo comprometimento do gestor e dos professores da instituição pelas melhorias nos índices educacionais e a implantação de ações que possam levar aos alunos educação de qualidade.

A lei n. 9.394/96 regulamenta a gestão democrática e determina a necessidade de que todas as escolas construam o seu projeto político-pedagógico. O artigo 12, inciso I, prevê o compromisso da instituição escolar na elaboração e execução da sua proposta pedagógica. No inciso VII do referido artigo consta o dever desta em informar aos pais sobre a execução de sua proposta pedagógica. $\mathrm{O}$ artigo 14 pressupõe a participação dos profissionais da educação na elaboração do projeto político-pedagógico da escola.

Contudo, passados vários anos da proposição deste novo formato na organização da educação brasileira, sob o viés da democratização da escola pública, permanecem muitos equívocos e dúvidas quanto à elaboração e a implantação do projeto políticopedagógico, um documento tão importante para a escola.

Muitos se pautaram, quando da elaboração do documento, em uma "deformação idealista, que valorizava apenas as ideias, os postulados filosóficos das ideias, as boas intenções, mas não se comprometiam com a efetiva alteração da realidade" (Vasconcellos, 1999, p. 60). O foco das preocupações dos gestores das escolas, nesta perspectiva, acabou sendo o de resolver as situações e as dificuldades conforme fossem surgindo, ou seja, a grande preocupação é manter a escola funcionando. Já para os professores a preocupação é essencialmente cumprir a carga horária e desenvolver todo o conteúdo. Os alunos se preocupam com avaliações e em passar de ano. Os pais não se preocupam, necessariamente, com o que e como os filhos estão aprendendo, mas que os filhos aprovem no final do ano.

Assim, o projeto político-pedagógico acaba sendo um documento necessário e determinado pela legislação, mas esquecido devido à rotina escolar e a necessidade de se resolver o que é urgente e individual, faltando o espaço do compartilhamento, da reflexão, da [re]definição de prioridades e posições, do planejamento e da [co]responsabilidade de ações coletivas a curto, médio e longo prazo. E é isto mesmo que o projeto político-pedagógico propõe à organização da escola: estabelecer prioridades, definir estratégias e ações coletivas que estejam voltadas para a função social da escola, resolver problemas e, portanto, transformar a prática da escola e a sua realidade. Nesta perspectiva, Libâneo (2008, p. 266) complementa:

o projeto político-pedagógico deve dar respostas consistentes a esta pergunta: quais objetivos devem ser formulados e quais ações concretas devem ser empreendidas para que a escola melhore o seu funcionamento, no sentido de propiciar aprendizagens mais eficazes, sólidas e duradouras dos alunos?

Entre as muitas características constitutivas de um projeto político-pedagógico, também, cabe salientar a participação de todos os segmentos que compõem a comunidade escolar - pais, alunos, professores, funcionários - na sua construção. A participação na construção e consecução do projeto político-pedagógico é o que confere 
legitimidade ao mesmo. Conforme afirma Veiga (2003, p. 277), "a legitimidade de um projeto político-pedagógico está estreitamente ligada ao grau e ao tipo de participação de todos os envolvidos com o processo educativo, o que requer continuidade de ações". Certamente que a visão dos gestores, professores e demais integrantes da comunidade escolar sobre este documento interfere nas decisões que se tomam na escola e na concretização de ações que visem à implantação das idéias e pressupostos contidos no projeto político-pedagógico.

Para tanto, nesta pesquisa problematizou-se acerca de quais são as concepções de gestores e demais integrantes da comunidade de uma escola de educação básica sobre a construção e consecução do projeto político-pedagógico, assim como as relações existentes entre as concepções acerca do projeto político-pedagógico da escola e as ações compartilhadas para a melhoria na qualidade de ensino nesta instituição. Nesta direção, buscou-se estabelecer possíveis relações entre as concepções existentes, o processo de construção do projeto político-pedagógico, a elaboração do documento e a sua efetiva implantação em uma escola de educação básica.

Assim, objetivou-se, de maneira geral, abordar e analisar acerca da relação existente entre as concepções e as ações dos gestores, professores e demais membros de uma escola pública de Três Passos, Rio Grande do Sul, quanto ao processo de construção e consecução do projeto político-pedagógico.

\section{Projeto político-pedagógico e sua centralidade na construção da escola como espaço de experiências de democracia}

Há polêmica em torno da terminologia adequada para intitular o projeto pedagógico de uma instituição educacional. É projeto pedagógico, projeto político-pedagógico ou proposta pedagógica? Qual a terminologia correta? Qual concepção permeia tal terminologia?

A lei n. 9.394/96, no artigo 12, define como proposta pedagógica e dá a incumbência da sua elaboração às instituições de ensino. Entretanto, a Resolução CNE/CEB n. 4, de 13 de julho de 2010, propõe a terminologia projeto político-pedagógico com ênfase ao aspecto central da educação relacionado à formação de cidadãos constituídos em uma escola democrática para todos e de qualidade social.

Para Veiga (2011) todo o projeto pedagógico é político, pois se articula com o compromisso sociopolítico, com interesses reais e coletivos da população escolar. Ele tem um compromisso com a formação do ser humano para a sociedade.

Segundo Saviani (apud Veiga, 2011, p. 13) "a dimensão política se cumpre na medida em que se realiza enquanto prática especificamente pedagógica". Ainda, em Veiga (2011), o projeto é pedagógico, pois é responsável pela formação do cidadão, no que a escola é responsável por definir ações educativas cumprindo seus propósitos de ter um cidadão responsável, crítico, criativo e compromissado.

Vasconcelos (1999), também prefere utilizar a nomenclatura projeto políticopedagógico, pois entende que esta terminologia representa de forma completa as "dimensões mais específicas da escola (comunitárias e administrativas, além da pedagógica), até as mais gerais (políticas, culturais, econômicas, etc)" (p. 169). 
Para que um projeto político-pedagógico, definido assim por Veiga (2011) e pela Resolução CNE/CEB n. 4/2010, seja de qualidade, esse termo deve ser utilizado por completo, pois pressupõe vivências relacionadas à democracia, a participação ativa de todos com permanente reflexão e discussão dos problemas da escola. Os termos político e pedagógico são, portanto, indissociáveis, pois propiciam a experiência democrática necessária à participação dos membros da comunidade escolar.

Mas o que vem a ser o projeto político-pedagógico? No que se constitui? O projeto político-pedagógico está relacionado à realidade de uma escola, o que pressupõe a participação de todos na elaboração deste documento que retrata os pontos fortes e as fragilidades e prioridades da escola, mas que, também, destaca os desafios a serem enfrentados no futuro e as ações que poderão ser efetivadas quando do enfrentamento desses desafios em atendimento as prioridades definidas com base no conhecimento da realidade. Portanto, construir e implantar participativamente trata-se de um dos pilares de sustentabilidade da gestão democrática nas escolas públicas.

Segundo Ferreira (2004, p. 1241), "gestão significa tomada de decisões, organização, direção. Relaciona-se com a atividade de impulsionar uma organização a atingir seus objetivos, cumprir suas responsabilidades." Assim, o sucesso de uma instituição está significativamente relacionado à mobilização de todos, de maneira conjunta, o que dá as pessoas oportunidade de sentirem-se responsáveis pelos resultados do trabalho coletivo da escola.

O projeto político-pedagógico, nesta perspectiva, constitui-se em importante mecanismo de participação e compartilhamento de decisões e ações colegiadas, devido ao seu poder articulador e organizador, por meio do engajamento de todos em busca de atingir os pressupostos teórico-metodológicos do ensino e aprendizagem, assim como soluções para os diferentes problemas da escola, fazendo com que todos tenham um sentimento de pertença ao grupo, estabelecendo-se uma coerência comum (Veiga, 2003).

O projeto político-pedagógico da escola, para além de ser um mero documento, se constitui num mecanismo de democratização porque potencializa à comunidade escolar relacionar e projetar a escola ideal com a escola real, tendo por base a inter-relação entre o presente e o futuro por meio da participação e responsabilização de todos. No entanto, como marco regulatório ou pressuposto legal, o projeto político-pedagógico corre o risco de ser burocratizado, transformando-se em um documento pronto e acabado, já que "a inovação de cunho regulatório ou técnico nega a diversidade de interesses e de atores que estão presentes" (Veiga, 2003, p. 271).

Ao participar da construção do projeto político-pedagógico da escola, a comunidade desenvolve um sentimento de [co]responsabilidade pela consecução do mesmo, ou seja, todos passam a sentir-se parte efetiva e importante para que a escola atinja seus objetivos educacionais. Ao mesmo tempo, a prática pedagógica passa a ser organizada em virtude dos objetivos que a comunidade escolar conclui serem fundamentais para essa escola, deixando de ser solta e sem significado para a vida do aluno. Por isso, como organizador do trabalho pedagógico da escola, o projeto político-pedagógico possibilita que os professores trabalhem com objetivos claros, relacionados aos objetivos da instituição. Os conteúdos escolares também deixam de serem fins em si mesmos, passando a ser conectados com a vida e com a realidade dos alunos. Dessa forma, com 
um ambiente democrático, ampla liberdade de trabalho para os professores e o compartilhamento das responsabilidades, passa a haver uma melhoria nos padrões de qualidade do trabalho pedagógico da escola.

Assim, percebemos que os objetivos relacionados à proposição e consecução coletiva e participativa de um projeto político-pedagógico traduzem a vontade da sociedade brasileira de mudanças e reconhecem o papel central da educação e da escola nesta necessária transformação. Por isso, não é possível que o projeto político pedagógico seja aceito pela comunidade escolar como um simples documento, como ampliação da burocracia escolar ou como se estivesse desligado do cotidiano escolar e tampouco é aceitável que os gestores ignorem a importância e a relevância do projetopolítico pedagógico para a organização e democratização da escola.

Nesta perspectiva, Veiga (2011) afirma que o projeto não pode ser algo construído, engavetado e, em seguida, encaminhado para as autoridades com a comprovação de que certa determinação do sistema de ensino foi cumprida. Vasconcellos (1999), também aponta esta questão como problemática central do planejamento escolar quando afirma, por exemplo, que com certa frequência os professores são chamados a determinadas tarefas de preenchimento de formulários com objetivos, conteúdos, estratégias e avaliação ou, ainda, para participarem da discussão do projeto político-pedagógico da escola sem, no entanto, haver um envolvimento com este projeto.

Luck (2011) argumenta que a realização de ações episódicas, que indicam a falta de visão do todo em relação aos processos educacionais, está relacionada com a falta de planejamento. A autora aponta que

essa falta, aliás, sustenta a atuação orientada por demandas e pressões
imediatistas, pelo ativismo e pela síndrome de "apagar incêndios" cuja
ocorrência, aliás, é comumente considerada como sendo resultado do
sistema e não da orientação e modo de agir espontaneista de pessoas,
com enfoque reativo, visando resultados próximos. (p. 83)

Assim, o planejamento da escola, que deveria estar relacionado com a construção e, frequentemente, à consecução do seu projeto político-pedagógico, permite que se supere a tendência de agir episodicamente, ou seja, em situações casuais "que resultam na construção de rotinas vazias de possibilidade de superação das dificuldades do cotidiano" (Luck, 2011, p. 83).

Sobre estas práticas casuais e ações não pensadas e planejadas no conjunto da escola, Vasconcellos (1999) aponta que, muitas vezes, se age mecanicamente, com o objetivo de cumprir os prazos exigidos pelas mantenedoras ou sistemas de ensino e o planejamento acaba ficando vazio de significados, sem sentido real para a escola. $O$ autor também discute alguns fatos observados nas escolas, com referência aos planos que são entregues e engavetados, quando coordenadores, orientadores e supervisores cobram exaustivamente os professores para que entreguem os seus planos: a prática do professor não leva em conta o que foi planejado, planos são copiados de livros, escolas fazem projetos e estes ficam esquecidos, escolas com belos textos na sua filosofia, no regimento, mas permanecendo práticas contraditórias, a escola constrói o projeto, mas com a mudança do governo ele acaba esquecido e engavetado, a escola faz o projeto 
político-pedagógico só porque a mantenedora fez esta exigência ou como forma de cumprir a lei.

De maneira geral o que Vasconcellos (1999) constata é a total descrença no planejamento. Mas por que isso acontece? Não seria o planejamento e decorrentes planos verdadeiros mecanismos de democratização e qualificação da escola básica e, sobretudo, de organização do trabalho docente? Como uma escola pode desenvolver com coerência seu papel social sem dar a devida importância ao planejamento?

Apesar de constatar a descrença dos educadores no planejamento, Vasconcellos (1999) reafirma a sua importância e destaca aspectos do planejamento que podem contribuir para uma escola mais democrática, como dar coerência à ação da instituição, integrando e mobilizando o coletivo de pessoas que perfazem a escola em torno de consensos, superação do caráter fragmentário das práticas em educação, ajudar a prever e resolver dificuldades, fortalecer o grupo para enfrentamento e superação de conflitos e contradições.

O projeto político-pedagógico, documento norteador do trabalho escolar e resultando de processos de planejamento coletivo e compartilhado, pode aglutinar e mobilizar as pessoas em torno de uma causa comum, ou seja, "ser um elemento estruturante da identidade da instituição" (Vasconcellos, 1999, p. 61).

Como plano global da instituição, como instrumento teórico-metodológico para intervenção e mudança da realidade, o projeto político-pedagógico é um elemento de organização e integração das atividades práticas na instituição, não devendo ficar basicamente no nível filosófico nem no nível de constatações sociológicas de um diagnóstico (Vasconcellos, 1999).

\section{Metodologia de pesquisa}

Esta pesquisa se ancorou em um estudo de caso de abordagem qualitativa. $\mathrm{Na}$ pesquisa qualitativa o objeto de estudo não representa uma generalização, ou seja, é impossível dizer que os resultados observados nesta instituição podem ser aplicados a outras e, por isso, não foi possível trabalhar com uma amostra representativa no sentido estatístico, nem mesmo as conclusões são passíveis de generalizações. Conforme aponta Paro (2011, p.11), "o fato de, no caso em estudo, encontrar-se presente determinado fenômeno ou particularidade do real, não significa que tal ocorrência seja generalizada; nem se trata de prová-lo".

Tendo em vista a metodologia adotada nesta pesquisa, foram utilizados como instrumentos de pesquisa, além da análise documental, entrevistas semi-estruturadas com os gestores e questionários com professores e pais membros do Conselho Escolar.

Duarte (2002) aponta que a pesquisa qualitativa demanda a realização de entrevistas, normalmente semi-estruturadas. Afirma que, para isso, a escolha dos sujeitos entrevistados é essencial, pois interfere diretamente na qualidade das informações a partir das quais são possíveis as construções das análises que permitem se chegar às conclusões mais amplas do problema de pesquisa proposto.

Chagas (2000) alerta para alguns possíveis condicionantes das respostas dos pesquisados, como: busca de conformidade ao grupo, tendência de imitação social, medo de julgamento do outro, busca de prestígio social, participação nas emoções coletivas, 
submissão aos estereótipos culturais, medo de mudanças. Por isso, priorizou-se, também, a análise documental já que "favorece o processo de maturação ou de evolução dos indivíduos, grupos, conceitos, conhecimentos, comportamentos, mentalidades, práticas, entre outros" (Cellard, 2008, apud Sá-Silva et al., 2009, p. 2) Assim, ao utilizar a análise documental, objetivou-se buscar uma compreensão do caminho percorrido pela escola ao longo dos anos com relação à construção e consecução compartilhada do projeto políticopedagógico, percebendo os avanços, retrocessos, contradições e a percepção que os sujeitos históricos têm.

Enquanto estudo de caso qualitativo, foi possível compreender os fenômenos estudados na perspectiva de um contexto específico e sob a ótica dos participantes da pesquisa, em que a análise de dados buscou entrelaçar os processos vividos na realidade empírica às discussões teóricas da temática em estudo, no sentido de desvelar dados relacionados ao problema de pesquisa levantado e aos objetivos propostos.

\section{As concepções e ações da comunidade escolar acerca do projeto político- pedagógico}

$\mathrm{Na}$ escola de educação básica em que esta pesquisa foi realizada encontram-se registros da coordenação pedagógica e da direção referentes às reuniões realizadas com professores, pais e entre pais e professores, nas quais se constatou diferentes graus participação dos pais e professores nas atividades da escola ao longo dos anos. Estes diferentes graus de participação estão diretamente relacionados com as concepções e práticas que os gestores e respectiva comunidade escolar possuem acerca do que é e da importância do projeto político-pedagógico.

Assim, o primeiro movimento da pesquisa em campo foi o de conhecer a trajetória da escola com relação à participação dos pais e professores nas decisões e, também, se a participação acontece de maneira democrática, bem como da evolução dos conceitos relativos ao planejamento da escola, principalmente no que se refere ao objeto desta pesquisa, o projeto político-pedagógico da escola.

Constatou-se, de maneira geral, que os registros da escola demonstram a participação da comunidade escolar, que se evidenciada por variações em diversos períodos nas formas como se dá esta participação e, assim, buscou-se verificar as concepções dos pesquisados.

Quando questionados sobre a sobre a importância do projeto político-pedagógico para a escola, os gestores apontaram que:

O PPP é a expressão da comunidade escolar e é fundamental, pois a escola é um contexto que tem que ser projetado. Sem planejamento, você faz muitas coisas que poderão evoluir, porém quando você faz coisas pensadas a tendência é surtir um efeito bem mais interessante. (Gestor 1)

No meu entendimento o PPP é fundamental para a Escola pois nele está a escola que temos, nossos desejos e nossas propostas para avançar. (Gestor 2) 
Em relação a como o projeto político-pedagógico foi [re]construído na escola, assim como qual o grau de participação da comunidade escolar neste processo, os gestores assim se manifestaram:

Pelas lembranças que tenho, há dez anos atrás as escolas passaram por um processo interessante de planejamento onde se envolveram vários setores da Escola, com participação efetiva de planejamento. Depois disso, foram feitas algumas adaptações [...] no nosso caso foi em 2010, porém sem a devida participação e envolvimento da comunidade escolar. A minha participação foi parcial, mais no sentido de sugerir e concordar, enquanto diretor (gestor), não foi qualificada como deveria. (Gestor 1)

O PPP escrito que temos, foi organizado por uma única pessoa e que não consta o todo da Escola [...] ficou explícito que não houve uma participação efetiva dos segmentos da Escola. Porém, quero destacar que há em nossa instituição uma avaliação constante de todas as atividades realizadas, avaliação esta primeiramente realizada pela equipe administrativa e pedagógica e, posteriormente, pelos professores. Assim, estes projetos são alterados sempre que se ache necessário. O que falta é reunir tudo num PPP. (Gestor 2)

Sobre as vantagens e as desvantagens da construção participativa do projeto político-pedagógico e se o planejamento é fator mobilizador ou não, os gestores assim se posicionaram:

Você só soma, contribui no processo quando de fato entende o que está fazendo e como está fazendo. A Escola é um grande conjunto de pessoas e de intenções, onde os gestores devem coordenar para que todos os envolvidos tenham objetivos comuns ou semelhantes [...] o planejamento é o ponto principal para o sucesso. (Gestor 1)

Penso que as vantagens são principalmente a condição de pertencimento daqueles que participaram da construção, ou seja, há um maior comprometimento dos segmentos. A maior desvantagem penso que seja a articulação entre os segmentos. Com certeza o planejamento é fator mobilizador porque é no planejamento que todos os detalhes são pensados e definidos os papéis de cada um. (Gestor 2)

Quando questionados sobre como acontece a participação dos professores na elaboração e consecução do projeto político-pedagógico da escola e se o mesmo acontece com os outros segmentos da comunidade escolar - pais, alunos e funcionários -, ou seja, se o nível de participação e comprometimento é o mesmo, o gestor 1 assim se manifestou:

Como já mencionei o nosso atual PPP não teve a efetiva participação de todos os segmentos, inclusive ao responder a pergunta estou me dando conta deste aspecto tão fundamental na vida escolar. Posso dizer que constato um interesse grande dos envolvidos com a escola, porem, devo tornar mais qualificada e objetiva a participação de cada segmento. 
Em relação à construção participativa do projeto político-pedagógico repercutir na sua implantação com compromisso coletivo pela comunidade, apenas o gestor 1 respondeu: "Com certeza, no momento em que você participa, entende o processo, o objetivo, o resultado é outro. Sempre, enquanto gestores, temos que ter um olhar para frente, a partir das avaliações previamente realizadas".

Ao serem questionados sobre se os professores utilizam o projeto político pedagógico como eixo norteador do seu trabalho pedagógico, no que isso repercute e se eles organizam seus planos de estudo e de trabalho com base no projeto políticopedagógico, o gestor 2 assim se posicionou:

Não aquele escrito, ou seja, os professores não utilizam o PPP escrito. Isto repercute que muitas vezes, o que está no documento PPP não vem a ser o real da Escola e o que é real não está no PPP.

Quando perguntados sobre se no dia-a-dia o projeto político-pedagógico da escola é colocado em prática e quais os pontos fortes e as fragilidades desse processo, o gestor 1 afirmou que

posso garantir que semanalmente temos reunião administrativa pedagógica que é o grande sustentáculo de toda a Escola, isto garante e viabiliza o PPP no seu conjunto geral, no entanto as atividades diárias fazem com que a gente esqueça de voltar a fonte, o PPP.

Com relação a como os pesquisados definem o tipo de gestão que acontece na escola e quais seus pontos positivos e quais aspectos que são necessários avançar, destaca-se a contribuição do gestor 1 :

Nosso grande objetivo é proporcionar aos profissionais envolvidos no processo um ambiente de tranquilidade e motivação a partir do convívio, da presença e da intervenção naqueles momentos mais críticos. Já trabalhei com vários tipos de gestores, e o que prefiro é o estilo responsabilidade. Se você está presente, dá o exemplo, está junto, dificilmente você precisa chamar a atenção das pessoas, porque você deu o exemplo, você deixou claro como é o trabalho e como deve ser. As pessoas produzem mais quando estão se sentindo bem, quando estão à vontade. Precisamos avançar em todos os sentidos, mas acredito que devemos evoluir mais em relação à participação e debate com todos os segmentos, pois como somos uma escola grande muitas vezes somos autossuficientes e se esquece de ouvir a todos.

Quanto à participação e o compromisso de todos os integrantes da comunidade escolar como um possível diferencial do trabalho pedagógico de uma escola e quais indicadores de qualidade eles percebem que repercutem na gestão democrática na escola, verificou-se que

podem ser vários aspectos. Uma gestão democrática influencia em todos, pois se você não é democrático você não dá exemplo de humildade. Se você é democrático, você dá o exemplo de humildade. Se você é democrático as pessoas terão mais liberdade, naturalmente o clima fica mais tranquilo, as pessoas se concentram mais, não ocorre violência. Com 
um clima mais tranquilo as pessoas estão mais propensas a aprender a partir das atividades vivenciadas. Mas não podemos pensar que uma pseudo tranquilidade seja sinônimo de coisa boa, as pessoas poderão estar acomodadas e não fazerem nada para mudar. (Gestor 1)

Sim, a participação pode ser um indicativo de qualidade, desde que se tenha claro o papel de cada segmento. Neste caso a equipe administrativa e pedagógica deve traduzir em ações viabilizando os anseios dos demais segmentos. A gestão democrática repercute no maior comprometimento/ parceria com os pais que se traduz também no comprometimento do aluno, comprometimento de todos os segmentos da escola. (Gestor 2)

Das ponderações dos gestores constatou-se que os mesmos percebem o projeto político-pedagógico como um documento oficial e como um importante instrumento, mas há, ainda, a compreensão de que, mesmo sem planejamento, a escola pode evoluir, porém, os pesquisados reconhecem que o planejamento tende a produzir resultados mais interessantes para o trabalho escolar. Também está presente o entendimento que o projeto político-pedagógico é um documento que expressa certa vontade da escola, através da descrição da realidade que se vivencia, os sonhos e desejos em relação ao futuro e as propostas para que se tenham avanços significativos.

Já quando questionados sobre como o projeto político-pedagógico da escola foi construído, há certa hesitação e está presente a autorreflexão, pois previamente os gestores abordam que o mesmo não aconteceu da forma como deveria. O projeto político-pedagógico elaborado pela comunidade escolar durante o processo denominado Constituinte Escolar, entre 1999 e 2002 sofreu alterações, mas sem a participação da comunidade, que não foi mais chamada a participar com engajamento.

Um dos condicionantes, talvez, seja a compreensão pelos professores de que a escola é assunto apenas dos professores, já que os pais não estariam qualificados para tal, o que pode ser verificado na manifestação do gestor 2 quando, ao responder à pergunta referente a forma como o gestor vê a participação de todos os segmentos no planejamento da escola e de se esta participação pode ser um indicativo de qualidade, responde que "sim, desde que se tenha claro o papel de cada um". Ou seja, subentendese que cada um exerce o seu papel, resguardando o aspecto pedagógico aos professores. O gestor ainda complementa, afirmando que "nesse caso, a equipe administrativa e pedagógica deve traduzir em ações viabilizando os anseios dos demais segmentos". Constata-se que o conceito que predomina é o da administração com forte centralização e divisão do trabalho na escola.

Está presente, também, a compreensão coletiva de que a organização da participação da comunidade escolar é um grande desafio já que as atividades rotineiras na escola - conversas periódicas com pais, conselhos de classe, questões disciplinares, questões financeiras, projetos da escola - envolvem os profissionais que atuam como gestores e coordenadores pedagógicos.

Há um sentimento de que o projeto político-pedagógico carece de legitimidade. $\mathrm{O}$ gestor 2 aponta que

vale ressaltar que existe em nossa instituição uma avaliação constante de todas as atividades realizadas, avaliação esta realizada primeiramente 
pela equipe administrativa - pedagógica e, posteriormente, pelos professores. Assim, esses projetos são alterados sempre que se ache necessário. O que falta é reunir tudo no PPP.

Transparece que existe um projeto político-pedagógico subjetivo, ou seja, uma escola que se quer, um modelo de sociedade e de ser humano e do caminho pedagógico a optar, mas há que se considerar que este entendimento pode ser reflexo da cultura própria da instituição, não perceptível para os que se encontram imersos nela, já que o projeto político pedagógico atual não foi construído pela comunidade escolar, como apontam os gestores 1 e 2 .

Fica evidente o conflito paradigmático, permanecendo ainda muito forte o conceito de administração, em que a condução dos destinos da instituição está atrelada a decisões do grupo que administra a escola, aqui denominado de equipe administrativa e pedagógica, para posteriormente ser apresentado aos professores.

Ao mesmo tempo em que prevalece o modelo da administração escolar, característico do paradigma técnico-científico e marcado por uma administração controladora e centralizadora, há a preocupação de estabelecer um diálogo com os professores, demonstrando um processo de mudança incipiente na instituição para o emergente paradigma da gestão.

A vigência do paradigma mais ligado ao conceito de administração está presente quando o gestor garante a realização de reuniões administrativas semanais com a equipe administrativa - direção, vice-direção e coordenação pedagógica - enfatizando que este é - grande sustentáculo da escola, o que garantiria e viabilizaria o projeto políticopedagógico. Evidentemente a compreensão aqui não é o da partilha e consecução entre os segmentos da escola, apesar de já haver certa evolução no sentido de que a centralização não se dá mais apenas na pessoa do diretor escolar, mas em uma equipe administrativa, o que talvez caracterize e sinalize em direção à mudança paradigmática, conforme aponta Luck (2011), mas, ainda, de forma pouco participativa.

Evidente que nada impede que a equipe gestora se reúna periodicamente para planejar e avaliar, mas o foco para a organização do trabalho escolar está na equipe gestora, com os professores e pais evidentemente possuindo papel secundário, quando $o$ que se espera de uma escola democrática é que a equipe gestora coordene e que o papel dos professores e pais seja ativo no processo decisório, em que todas as decisões sejam tomadas no coletivo da escola.

Além disso, Luck (2011) destaca algumas consequências muito negativas, a médio e longo prazo, da participação passiva dos professores considerando o aspecto sociocultural dessa prática: “i) destrói qualquer possiblidade de colaboração benéfica; ii) promove o descrédito nas ações da direção e nas pessoas que detém autoridade; iii) gera desconfiança e descrédito; iiii) destrói as sementes e motivações da participação efetiva existentes nas pessoas" (p. 33)

O gestor 2 aponta que uma das maiores vantagens do projeto político-pedagógico é que a construção e implantação compartilhada permite que todos desenvolvam um sentimento de pertença daqueles que participam da construção fazendo com que haja um maior comprometimento de todos os segmentos da escola, ao mesmo tempo aponta que a principal desvantagem da construção coletiva do projeto político-pedagógico é a 
articulação entre os segmentos. Portanto, permanece um conflito evidente entre o que se pensa sobre o projeto político-pedagógico e as ações realmente implementadas na escola em relação a este documento. Este conflito está, também, presente na fala do Gestor 2, quando aponta que o que está no projeto político pedagógico não necessariamente corresponde ao que é real e o que é real, muitas vezes, não está elencado no projeto político-pedagógico, evidenciando que este não é o documento norteador das atividades da escola e que as ações são pensadas de forma esporádica, por um pequeno grupo de pessoas, para posteriormente serem referendadas em reuniões marcadas por uma participação parcial e passiva.

Estas ações esporádicas, conforme Luck (2011), que podem trazer alguns resultados positivos, estão associadas à falta de visão do conjunto da escola e sustentam as práticas orientadas por pressões imediatistas, ao que a autora se refere como a síndrome de apagar incêndios. Assim, o projeto político-pedagógico não é o articulador que se pretende que seja, mas apenas mais um documento da escola. A própria visão que se tem do mesmo na escola é de que se trata de mais burocracia e que este documento não está ligado nem relacionado com a prática pedagógica dos professores.

Nesta pesquisa foi utilizado um questionário estruturado com os professores que representam este segmento junto ao Conselho Escolar. Neste sentido, quando questionados acerca do entendimento que possuem sobre a importância do projeto político-pedagógico à escola verifica-se que para o professor 1 o projeto políticopedagógico é fruto "do planejamento das ações pedagógicas, a concretização do que queremos para a nossa escola, são os nossos sonhos e metas [...] é a partir dele que o gestor e a comunidade escolar baseiam-se para normatizar e tomar decisões."

Quanto à forma como o projeto político-pedagógico foi [re]construído na escola e a percepção do grau de participação da comunidade escolar neste processo o professor 1 argumenta que

a cada ano planejamos as nossas ações, avaliamos o que deu certo e melhoramos as dificuldades. Nas reuniões pedagógicas avaliamos com os professores o PPP, e com os pais, no início do ano letivo, apresentamos nossas propostas, ouvindo sugestões dos pais. Mas a execução fica sob responsabilidade da Equipe Diretiva e Coordenação, assim como o registro do PPP. Muita coisa é feita na prática, mas não é registrada.

O professor 2 informou que o processo de [re]construção do projeto políticopedagógico acontece

através de reuniões e participação dos membros que compõem a coordenação. O grau de participação da comunidade escolar dá-se através do Conselho Escolar com seus representantes, a minha participação é por meio do Conselho Escolar, pois faço parte como membro deste Conselho no segmento professores.

Os professores também foram questionados sobre as vantagens e desvantagens percebidas pelos mesmos quanto à construção participativa do projeto políticopedagógico e se o planejamento pode ser considerado fator mobilizador. O professor 1 disse que 
ouvir a comunidade escolar é muito importante, portanto a construção do PPP deve ser participativa, onde todos se sintam importantes e responsáveis pela Escola. A presença dos pais na vida escolar dos filhos é fator imprescindivel para a boa aprendizagem. Um bom planejamento consegue envolver e comprometer a todos.

O professor 2 destacou que "a comunidade escolar tem o direito de opinar na construção do PPP, a participação é indispensável, por isso é um fator mobilizador."

Quando questionados sobre como se efetivou a participação dos professores na elaboração e consecução do projeto político-pedagógico da escola e se o mesmo aconteceu com os outros segmentos da comunidade escolar - pais, alunos e funcionários - e se esta ocorreu de forma igualitária entre os segmentos da escola, o professor 1 respondeu que

através das reuniões pedagógicas e avaliações anuais, com sugestões, ideias e novas contribuições. Nem sempre a participação envolve o comprometimento. De alguma forma sabem como as coisas funcionam, portanto são parte do processo e responsáveis por seus filhos. Quanto aos funcionários sinto que a participação poderia melhorar.

Quando questionados quanto a sua participação nas reuniões que acontecem na escola, afirmaram que "Não participo de todas porque sou membro do Conselho Escolar, participo destes e das reuniões que a direção realiza com os professores" (professor 2) e que "sim, além de professora, sou coordenadora e mãe de aluna. Sou membro ativo" (professor 1)

Também, perguntou-se acerca de a participação de todos os integrantes da comunidade escolar ser um indicativo de qualidade do trabalho pedagógico e quais indicadores de qualidade poderiam estar repercutindo à gestão democrática na escola. Os professores responderam:

Valorização do trabalho docente; aprendizagem significativa e efetiva do aluno; melhoria das condições físicas e de acessibilidade da escola; responsabilidade, participação e comprometimento da comunidade escolar; respeito às ideias individuais e decisões coletivas; descentralização da gestão, experiências democráticas, autonomia, transparência, pluralidade; preservação do patrimônio; interação escola e comunidade. (Professor 1)

No meu ponto de vista repercute no bom funcionamento da escola em todos os sentidos e segmentos. Haja vista que a escola é referência na região, alunos de outros municípios vêm estudar aqui. As notas no Enem dos alunos que são da Escola e o ingresso em universidades através da nota no Enem. (Professor 2)

Ao ser questionada sobre as vantagens e desvantagens da construção participativa do projeto político-pedagógico o professor 1 afirmou que "ouvir a comunidade escolar é muito importante, portanto a construção do PPP deve ser participativa, em que todos se sintam importantes e responsáveis pela escola" e que "um bom planejamento consegue 
envolver e comprometer a todos." Porém, apontou que "nem sempre a participação envolve o comprometimento, mas os pais são comunicados e orientados. De alguma forma sabem como as coisas funcionam, portanto, são parte do processo." Nesta perspectiva, Paro (2011) e Luck $(2010,2011)$ argumentam que este não é o tipo de participação que se quer em uma escola democrática e de qualidade social.

Paro (2012) aborda o porquê desta não ser a participação ideal em uma escola pública. Em relação ao sentimento muito presente entre os educadores de que não cabe aos pais participar das decisões que se tomam na escola, sendo que o autor coloca que esta lógica desconsidera a evidente continuidade entre a educação familiar e a educação escolar. Também destaca que embora a função da escola seja de prestar um serviço público, nem sempre o Estado oferece as condições necessárias para que esta aconteça com qualidade, assim, uma maior presença dos pais poderia impulsionar o Estado a oferecer um ensino de melhor qualidade.

No entanto a ideia que professores e gestores têm sobre esta participação é, ainda, pouco próxima daquela que caracteriza um espaço democrático, e isto fica evidente nas falas que indicam que os pais são comunicados e, por isso, de alguma forma participariam das decisões da escola. São participações que podem ser identificadas com as classificações de Luck (2011): participação como presença, participação como expressão verbal e discussão de ideias e participação como representação. O professor 2, integrante do Conselho Escolar, deixa explícito o seu entendimento sobre a participação dos professores quanto a participação da comunidade: "O grau de participação da comunidade escolar dá-se através do Conselho Escolar com seus representantes, a minha participação é por meio do Conselho Escolar, pois faço parte como membro deste Conselho no segmento professor".

Acerca deste tipo de participação, Paro (2012) considera que aceitar que a participação dos pais seja restrita ao conselho representativo seria o mesmo que presumir que o eleitor, após eleger seu deputado, delegue ao mesmo amplos poderes, deixando de participar ativamente das decisões as quais se tomam na sociedade e, portanto, interferem na vida dos mesmos.

A compreensão de Luck (2011) corrobora com esta concepção, ao demonstrar que apesar da representatividade por segmento ser comum nas sociedades democráticas, pode ser considerada como uma falsa participação, "um arremedo de participação" (Luck, 2011, p. 42). Tal afirmação apoia-se no conceito original de participação, o do governo do povo, pelo povo e para o povo, através do qual se sustenta que participar não significa delegar poderes a alguém que possa agir em seu nome, desresponsabilizando-se pelo mesmo. Sobre estas participações casuístas, sem mudança na compreensão que os gestores e educadores possuem sobre a importância da participação dos pais, Paro (2011) afirma que "uma medida isolada, que não seja resultado de práticas que evidenciam uma nova postura de respeito e consideração para os pais e alunos e a população circunvizinha, dificilmente conseguirá resultados positivos." (p. 197)

Também foi aplicado um questionário a um pai membro do Conselho Escolar, na função de presidente deste Conselho. Assim, quando questionado acerca de como percebe a participação dos pais na escola, informou que, 
na minha opinião, a participação dos pais na escola é bastante limitada. Muitos pais não querem comprometer seu tempo pessoal com a Escola, sob a alegação de falta de tempo, e se limitam a participar das reuniões de início e encerramento do ano letivo, das apresentações dos filhos (quando o mesmo participa), das festas da escola e das atividades de classe do filho. Entendo que uma parcela dos pais, assim que convidados, estariam dispostos a colaborar com a direção da escola, seja na participação do CPM, do Conselho Escolar, na discussão das melhorias materiais da Escola, na discussão do projeto pedagógico da escola, pois entendem que a Escola do seu filho, além da estrutura física em que se constitui, também é um local de discussão e de capacitação que pode levar a melhoria da qualidade do ensino.

Sobre em que momento participa da escola do seu filho e como esta acontece, o pai relatou que:

Acho que os pais são chamados a participar das atividades da Escola ou a trabalhar nas festas que a escola promove, porém, são poucas as vezes que os pais são convidados a participar das decisões ou dos rumos que a Escola pretende tomar.

Também, perguntou-se sobre como este pai contribui como membro do Conselho Escolar e se poderia auxiliar mais a escola:

Participo do Conselho Escolar na qualidade de presidente. Ao assumir minhas funções de presidente do Conselho Escolar solicitei a direção da Escola quais seriam minhas atribuições legais. Fui informado de que iria receber material para estudo (acho que o Regimento da Escola e o PPP), mas até o momento não tive acesso ao material. Entendo que poderia contribuir muito mais com a Escola, não apenas com meu tempo pessoal, mas também com minha experiência profissional e com a postura de quem enxerga a escola de fora para dentro para sugerir, discutir, para fazer a crítica construtiva, a fim de fazer da nossa escola aquele espaço que sonhamos e queremos. Entendo que a direção, coordenação, o corpo docente e os funcionários enxergam a Escola com uma visão interna, apenas por dentro, e se limitam a vê-la a partir da sua ótica pessoal e dos seus interesses particulares.

O pai se manifestou sobre como entende ser o projeto político-pedagógico da escola e sua importância para a qualidade de ensino:

Entendo por projeto político-pedagógico o plano de ações e objetivos da escola a médio e longo prazo. É através do PPP que a escola apresenta sua visão, planeja sua missão e os valores que constituem seu projeto educativo.

No mesmo sentido, foi questionado se conhece o projeto político-pedagógico da escola, se o ajudou a construir e como foi este processo:

Ainda que membro do Conselho Escolar há cerca de dois anos, sinceramente, não conheço o PPP da escola, tampouco ajudei a construílo, por isso não posso opinar como foi o processo de construção do PPP 
do Instituto Estadual de Educação Érico Veríssimo de Três Passos. Ter acesso ao PPP, estudá-lo e conhecê-lo a fundo seria a primeira e principal missão de todos os membros do Conselho Escolar, do CPM, da Direção e da Coordenação Pedagógica da escola.

Quanto a sua compreensão sobre o nível de participação e comprometimento dos outros segmentos da comunidade escolar - professores, alunos e funcionários - na elaboração e implantação do projeto político-pedagógico da escola, o pai assim se manifestou:

Acho que houve a participação dos gestores e professores na elaboração do PPP, porém, nestes dois anos que participo do Conselho Escolar participei diretamente ou tive a informação de que o PPP foi objeto de uma avaliação contínua, se a Escola está ou não cumprindo com suas ações e objetivos ou se há necessidade de reavaliar o PPP para adaptá-lo as mudanças na sociedade. Tampouco posso opinar como foi a participação dos demais segmentos da comunidade escolar (alunos e funcionários) na elaboração e implantação do PPP. Mas comparando com a participação dos membros do Conselho Escolar atual, da qual posso externar minha opinião, acho que a participação dos alunos e servidores também foi pequena. Quanto ao comprometimento, se você não conhece o plano de metas e ações da escola, entendo que não há o desejado comprometimento ou este fica sobremaneira prejudicado.

Com relação as atividades que o pai percebe estarem relacionadas à implantação do projeto político-pedagógico da escola, fez a seguinte ponderação:

\begin{abstract}
Embora reitero não ter conhecimento nem ter tido acesso ao conteúdo do PPP, creio que as diversas atividades e ações desenvolvidas pela Escola durante o ano letivo estão relacionadas ao disposto no PPP, tais como: realização da gincana anual da escola; edição do livro das séries iniciais e realização da noite de autógrafos; melhorias nos espaços físicos e salas de aula da escola; capacitação do corpo docente; reuniões da coordenação pedagógica; atividades esportivas, culturais, reuniões com os pais dos alunos; apresentações em comemoração ao dia das mães e dos pais; reuniões com o CPM e o Conselho Escolar.
\end{abstract}

Verificou-se, pelas contribuições do pesquisado, que sua participação acontece na forma representativa do Conselho Escolar e que o mesmo não percebe a participação dos outros pais ou outros segmentos da escola nos processos de tomada de decisão, o que fica mais evidente quando se refere à participação do seu segmento quando de festas e outras atividades da escola, mas poucas vezes quando da necessidade de tomada de decisões sobre os rumos que a escola tem tomado ou necessita tomar.

Paro (2011) afirma que permanecem muitos erros e equívocos na compreensão dos gestores sobre como deve se dar a participação da comunidade na escola e de quais os limites desta participação. Afirma que é muito presente a compreensão de que os pais devem ajudar a escola com sua manutenção, ou em festas cujo principal objetivo é arrecadar fundos para manutenção e melhorias na estrutura da escola. Assim, percebe-se que a manifestação do pai está relacionada a esta visão de participação da comunidade desligada dos problemas pedagógicos da escola. 
O pesquisado aponta que os pais, por sua vez, também não "querem comprometer seu tempo pessoal com a Escola, sob a alegação de falta de tempo, e se limitam a participar das reuniões de início e encerramento do ano letivo, das apresentações dos filhos". Sobre isso, Paro (2011) afirma que as dificuldades de organização também dizem respeito ao oferecimento de tempo e espaço para que os representantes do Conselho Escolar "possam se reunir com seus representados e, assim, possam levar para as reuniões os reais interesses e pleitos desses últimos" (Paro, 2011, p. 199). No entanto, permanece entre os professores a concepção de que a maior dificuldade relacionada a participação dos pais nas decisões é a falta de interesse por parte destes e a dificuldade de encontrar formas de estimulá-los.

Acerca destas ideias correntes entre os professores e gestores, o pai afirmou o contrário, já que, segundo ele, uma boa parcela dos pais aceitaria participar mais ativamente das decisões que são tomadas na escola:

Entendo que uma parcela dos pais, assim que convidados, estariam dispostos a colaborar com a direção da Escola, seja na participação do CPM, do Conselho Escolar, na discussão das melhorias materiais da Escola, na discussão do projeto pedagógico da Escola, pois entendem que a Escola do seu filho, além da estrutura física em que se constitui, também é um local de discussão e de capacitação que pode levar a melhoria da qualidade do ensino.

Quando questionado sobre sua compreensão do projeto político-pedagógico da escola, o pai evidenciou ter conhecimento sobre o significado do mesmo e, também, demonstrou acreditar que, apesar de não conhecer este importante documento, ele é utilizado pela escola para atingir os objetivos da mesma, pois é "através do PPP que a escola apresenta sua visão, planeja sua missão e os valores que constituem seu projeto educativo" (pai).

Paro (2011) se refere ao papel secundário delegado ao Conselho Escolar na gestão da escola: "O conselho de escola é órgão deliberativo que deve fazer parte da direção escolar, mas se mostra muito pouco atuante, como costuma acontecer em grande parte das escolas" (p. 58). Este papel secundário do Conselho Escolar também pode ser evidenciado na manifestação do pai, uma vez que o mesmo sinaliza não ter conhecimento do projeto político-pedagógico, mesmo tendo o solicitado, ao mesmo tempo em que apontou a pouca participação da comunidade no Conselho Escolar.

\section{Considerações finais}

Este trabalho oportunizou compreender como a visão dos gestores, professores e demais integrantes da comunidade escolar sobre o projeto político pedagógico interfere nas decisões que se tomam na escola básica e na concretização de ações que visem a implantação dos pressupostos e prioridades contidos no projeto político pedagógico.

Para isso, desenvolveu-se uma análise documental nos arquivos de atas e registros da direção e coordenação pedagógica da escola, referentes a reuniões com pais e com professores e, também, encontros entre pais e professores, além de entrevistas semiestruturadas com gestores e questionários com professores e pais, estes membros do Conselho Escolar. 
Constatou-se que a escola de educação básica, objeto desta pesquisa, passou por momentos marcados por graus de participação da comunidade escolar. Constatou-se, também, que estes diferentes graus de participação estão relacionados às concepções que os gestores possuem acerca da participação da comunidade escolar. Assim, os gestores podem diretamente interferir na maior ou menor participação da comunidade na escola. Percebeu-se que, quando chamados a participar, uma parcela significativa dos pais responde com sua participação ativa na construção e consecução do projeto políticopedagógico. No entanto, observa-se, também, que os gestores não possuem conceitos de participação diretamente relacionados a princípios democráticos.

Apesar dos avanços como a existência de órgãos colegiados e do compartilhamento das decisões entre direção, vice-direção, coordenação pedagógica e orientação educacional, os professores precisam assumir protagonismo direto na construção do projeto político-pedagógico da escola e as decisões, apesar de não mais centradas apenas na figura do diretor, necessitam se constituir compartilhadas com a comunidade escolar.

A compreensão de que a participação da comunidade escolar acontece pelo Conselho Escolar é muito presente entre professores, pais e gestores e há dificuldade de vislumbrar outras formas, também democráticas, de envolver pais e professores na implantação compartilhada do projeto político-pedagógico.

O projeto político-pedagógico é um importante documento norteador das intenções e ações da escola, mas, ao mesmo tempo, é preciso ser mais conhecido pelos professores, deixando de se constituir apenas um marco regulatório burocrático. O projeto políticopedagógico ainda não tem sido utilizado como um mecanismo de participação e articulação do trabalho escolar. Apesar de muitas práticas escolares produzirem bons resultados, está muito presente um sentimento de que estas são desligadas umas das outras.

Assim, constatou-se que o projeto político-pedagógico ainda precisa ser mais conhecido, estudado e estar coerente com as práticas administrativo-pedagógicas da escola, bem como seu processo de construção e consecução requer estar alinhados aos princípios de gestão democrática.

No transcorrer da pesquisa, passou-se a compreender acerca da importância do projeto político-pedagógico para a organização das escolas, tendo em vista que é um dos principais mecanismos de democratização da gestão escolar. Quando construído, compreendido e assumido pela comunidade, certamente, poderá constituir-se como eixo norteador de ações educacionais voltadas para a qualidade de ensino e aprendizagem.

Verificou-se, assim, como se institui esse processo de construção, se compartilhado e participativo, ou, até mesmo, se fragmentado. Entretanto, mesmo não sendo possível obter a coletividade na comunidade escolar, é preciso a visão diagnóstica reconhecendo as limitações, fragilidades e necessidades da escola, bem como as políticas públicas para a educação, nas ações e envolvidos que mobilizam a construção do projeto políticopedagógico. 


\section{Referências}

BRASIL. Lei n. 9.394/96. Lei de Diretrizes e Bases da Educação Nacional, de 20 de dezembro de 1996. Disponível em: <http://portal.mec.gov.br/arquivos/pdf/ldb.pdf>. Acesso em 29 abr., 2012.

BRASIL. Resolução CNE/CEB n. 4, de 13 de julho de 2010. Disponível em <http://portal. mec.gov.brindex.phpltemid=866\&id=14906\&option=com content\&view=article>. Acesso em 3 jun., 2012

CHAGAS, Anivaldo Tadeu Roston Chagas. O questionário na pesquisa científica. Revista eletrônica Administração Online, São Paulo, v. 1, n. 1, 2000. Disponível em <http://www. fecap.br/admonline/art11/anival.htm> Acesso em 4 nov., 2012

DUARTE, Rosália. Pesquisa qualitativa: reflexões sobre o trabalho de campo. Cadernos de Pesquisa, n. 115, 2002, p. 139-154.

FERREIRA, Naura Syria Carapeto. Repensando e ressignificando a gestão democrática da educação na cultura globalizada. Educação e Sociedade. Campinas, v. 25, n. 89, 2004, p. 1227-1249.

LIBÂNEO, José Carlos. Organização e gestão da escola: teoria e prática. Goiânia: Alternativa, 2008.

LUCK, Heloísa. A gestão participativa na escola. Petrópolis: Vozes, 2011.

LUCK, Heloísa. Concepções e processos democráticos de gestão educacional. Petrópolis: Vozes, 2011.

LUCK, Heloísa. Gestão educacional: uma questão de paradigmática. Petrópolis: Vozes, 2011.

PARO, Victor Henrique. Crítica da estrutura da escola. São Paulo: Cortez, 2011.

SÁ-SILVA, Jackson Ronie; ALMEIDA, Cristóvão Domingos de; GUINDANI, Joel Felipe. Pesquisa documental: pistas teóricas e metodológicas. Revista Brasileira de História \& Ciências Sociais, ano 1, n. 1, 2009, p. 1-15. Disponível em: http://rbhcs.com/ indexarquivos/Artigo.Pesquisa\%20documental.pdf Acesso em 4 nov., 2012.

VASCONCELLOS, Celso dos Santos. Planejamento: projeto de ensino-aprendizagem e projeto político-pedagógico. São Paulo: Libertad, 1999.

VEIGA, IIma Passos Alencastro. Inovações e projeto político-pedagógico: uma relação regulatória ou emancipatória? Cadernos Cedes. Campinas, v. 23, n. 61, 2003, p. 267-281.

VEIGA, IIma Passos Alencastro. Projeto político-pedagógico da escola: uma construção coletiva. In: VEIGA, Ilma Passos Alencastro. Projeto político-pedagógico da escola: uma construção possível. Campinas: Papirus, 2011.

Samuel Robaert é estudante do curso de mestrado em Educação no Programa de Pós Graduação em Educação da Universidade Federal de Santa Maria e professor no Instituto Federal Farroupilha - campus Santo Augusto - RS.

Rua da Bandeira, 24 - 98600-000 - Três Passos, RS - Brasil.

E-mail: samu robaert@yahoo.com.br 
Marilene Gabriel Dalla Corte é doutora em Educação e professora adjunta no Departamento de Administração Escolar do Centro de Educação da Universidade Federal de Santa Maria.

Estr. Mun. Angelo Berleze, 565 - 97095-640 - Santa Maria - RS.

E-mail: marilenedallacorte@gmail.com

Recebido em 9 de maio de 2014.

Aceito em 14 de junho de 2014. 